\title{
Initial Experience of
}

Laparoendoscopic Single-Site Radical Prostatectomy Requiring Well-Equipped Appliances and a Skilled Technique

\author{
Joo Yong Lee ${ }^{a}$ U-Syn Hab ${ }^{b}$ Seung Wook Lee \\ ${ }^{a}$ Department of Urology, Hanyang University College of Medicine, ${ }^{b}$ The Catholic \\ University of Korea College of Medicine, and 'Eulji Hospital, Eulji University \\ College of Medicine, Seoul, Korea
}

\section{Key Words}

Laparoscopy $\cdot$ Prostate cancer $\cdot$ Radical prostatectomy

\begin{abstract}
We report an initial experience in laparoendoscopic single-site radical prostatectomy (LESSRP) using a homemade single-port device for prostate cancer. A 63-year-old man was diagnosed with prostate cancer. The patient underwent LESSRP using an Alexis ${ }^{\circledR}$ wound retractor, which was inserted through an umbilical incision. A homemade singleport device was made by fixing a $61 / 2$ surgical glove to the retractor's outer ring and securing the glove finger to the end of 4 trocars with a tie. Using the flexible laparoscopic and rigid instruments, LESSRP was performed using a procedure similar to conventional laparoscopic radical prostatectomy (LRP). In the current case, we could not perform complete LESSRP, so we report our initial experience and consider the reason why laparoendoscopic single-site surgery was converted to conventional LRP.
\end{abstract}

\section{Introduction}

Since Clayman et al. [1] first introduced laparoscopic surgery in the field of urology, progress in laparoscopic radical surgery has been remarkable in urologic oncology. Advances in surgical instruments and techniques have made incision, resection and coagulation easier, enabling the application of this procedure to be extended up to radical prostatectomy. Laparoscopic radical prostatectomy (LRP) has been widely used as a minimally invasive surgery since its introduction by Schuessler et al. [2]. The advantages 
of LRP include decreased postoperative pain, earlier return to daily activities due to minimally invasive surgical wound, shorter hospital stay, decreased blood loss, earlier recovery of potency and an oncological outcome similar to that of open radical prostatectomy (ORP) [3]. Abbou et al. [4] demonstrated that LRP is beneficial in the preservation of the urethral sphincter and nerves due to the wide surgical field, resulting in the restoration of continence and potency. Recently, laparoendoscopic single-site (LESS) surgery, by which surgical instruments can be introduced through a single incision, has improved the esthetic outcome and has replaced conventional laparoscopic surgery. Kaouk et al. [5] have reported that the LESS surgery technique also allows for earlier recovery. We report herein our initial experience and reason for conversion of LESS radical prostatectomy (LESSRP), using a homemade single-port device, to conventional LRP, with a schematic surgical illustration.

\section{Case Report}

A 63-year-old man presented with a 3-year history of voiding difficulty. The patient complained of frequency intervals of 1-2 $\mathrm{h}$ and nocturia of 3 times per night. Before this presentation, digital rectal examination had revealed bilateral enlargement of the prostatic lobes. Under a clinical diagnosis of benign prostate hyperplasia, he had been administered tamsulosin $0.2 \mathrm{mg}$ once a day for 2 years. After medical treatment, his serum prostate-specific antigen was $4.11 \mathrm{ng} / \mathrm{ml}$, which was a 4 -fold increase from the baseline prostate-specific antigen. He underwent a 12-core transrectal ultrasonography (TRUS)guided prostate biopsy, which showed a localized prostate cancer $(\mathrm{PCa})$ with a Gleason score of $7(3+4)$ in the bilateral peripheral zones. Magnetic resonance imaging for tumor staging revealed benign prostate hyperplasia and hematoma due to TRUS-guided biopsy, and bone scintigraphy displayed no bony metastasis. We decided to perform a radical prostatectomy under a diagnosis of localized PCa (clinical stage T2cN0M0). Informed consent was obtained after a complete description of the various surgical procedures including ORP, LRP, robot-assisted LRP (RALRP) and LESSRP using a homemade single-port device.

Under general anesthesia, a urethral Foley catheter was inserted in a supine low lithotomy position. The operator stood on the left side of the operating table, and 2 assistants stood on the right side. After a $3-\mathrm{cm}$ vertical skin incision was made in a crease just superior to the umbilicus, dissection was performed up to the peritoneum. A homemade single-port device was prepared using a small Alexis ${ }^{\circledR}$ wound retractor (Applied Medical, Rancho, Santa Margarita, Calif., USA) and a powder-free surgical glove (Triplex P-free Glove ${ }^{\circledR}$, KM Healthcare, Guri, Korea). After the wound retractor was inserted through the incision site, the ring of the wound retractor was covered with a $6^{1} / 2$ surgical glove, which was rolled over around the ring, and the glove was forced to completely touch the abdominal wall. After cutting out 3 fingers of the glove, two 12-mm trocars and one 5-mm trocar were fixed with 1-0 silk suture material. In a steep Trendelenburg position, intraperitoneal $\mathrm{CO}_{2}$ pressure was maintained at 15 $\mathrm{mm} \mathrm{Hg}$. A 30-degree 10-mm rigid laparoscope was introduced into the center trocar, and the other 2 trocars were used for flexible laparoscopic instruments (LaparoAngle ${ }^{\circledR}$, Cambrige Endo, Framingham, Mass., USA) and conventional rigid instruments. LESSRP was performed using the homemade singleport device in the same manner as conventional LRP (fig. 1). An additional $12-\mathrm{mm}$ port was created by cutting out another finger of the surgical glove because there was interference between the flexible laparoscopic instruments during vesicourethral anastomosis after the resection of the prostate and seminal vesicle ( $\underline{\text { fig. } 2}$ ). However, since the working space for the anastomosis and adequate angles between the instruments was not maintained, another two $12-\mathrm{mm}$ transcutaneous ports were created above the anterior superior iliac spine on both sides, so that the procedure was converted to conventional LRP (fig. 3). After the completion of anastomosis, the absence of urine leakage was confirmed by a saline test. There were no intraoperative and postoperative complications. The urethral Foley catheter was maintained for 7 postoperative days. When a cystography performed 7 days after surgery showed no urine leakage, the catheter was removed. The resected prostate measured $5.0 \times 4.0 \times$ $4.5 \mathrm{~cm}$ (fig. 4), and the pathological examination of the surgical specimen revealed PCa with a Gleason score of $7(3+4)$ reflecting prostatic cancer invasion (pT3a). Until now, the patient has been healthy for nine months postoperatively and treated with GnRH agonists and antiandrogens. 


\begin{tabular}{|c|c|c|c|}
\hline $\begin{array}{c}\text { Case Reports in } \\
\text { Oncolous }\end{array}$ & \begin{tabular}{|l} 
Case Rep Oncol 2010;3:445-450 \\
DOI: $10.1159 / 000322818$
\end{tabular} & $\begin{array}{l}\text { Published online: } \\
\text { December 1, } 2010\end{array}$ & $\begin{array}{l}\text { () } 2010 \text { S. Karger AG, Basel } \\
\text { ISSN 1662-6575 } \\
\text { www.karger.com/cro }\end{array}$ \\
\hline
\end{tabular}

\section{Discussion}

ORP through the retropubic approach is the standard treatment of localized PCa. However, this method has the disadvantages of difficulty in maintaining the surgical field, intraoperative bleeding, postoperative pain/thromboembolism/incontinence/erectile dysfunction and increased hospitalization [2]. To solve these problems of ORP, there is currently a tendency for conversion to LRP or RALRP. However, LRP has the disadvantages of a longer operation time and the necessity for good familiarity with the surgical procedure. The disadvantages of RALRP are the requirement of an expensive da Vinci robotic system (Intuitive Surgical, Mountain View, Calif., USA) and a high surgeon's fee compared to ORP or LRP in Korea. Previous studies have proposed that the LRP may aid in the fine dissection of neurovascular bundles and facilitate a higher quality of watertight vesicourethral anastomosis [6].

Recent operations have been directed toward scar-free procedures, and thus new terms, 'natural orifice translumenal endoscopic surgery' (NOTES ${ }^{\mathrm{TM}}$ ) or 'LESS' have been coined. LESS surgery, a laparoscopic surgery through a single incision site, was proposed as a new term after the 2008 Laparoendoscopic Single-Site Surgery Consortium for Assessment and Research (LESSCAR) [7]. In the field of urology, Rane et al. [8] reported the first case of LESS nephrectomy using an R-port (Advanced Surgical Concepts, Dublin, Ireland) at the 2007 World Congress of Endourology Meeting. Thereafter, many surgeons have applied this technique to various urological diseases and have reported its usefulness and safety. Sotelo et al. [9] stated that LESS simple prostatectomy using an R-port is more difficult than the conventional laparoscopic procedure with a total operation time of 120 min. Kaouk et al. [10] reported 4 cases of LESSRP using a Uni-X single laparoscopic port system (Pnavel Systems, Morganville, N.J., USA). They reported a mean operation time of $285 \mathrm{~min}$, a mean estimated blood loss of $287 \mathrm{ml}$ and a mean duration of catheter placement of 14 days. In our LESSRP using a homemade single-port device together with LRP, the operation time was $610 \mathrm{~min}$, and the estimated blood loss was approximately $600 \mathrm{ml}$. The urethral Foley catheter was removed 7 days after surgery. In radical prostatectomy, we could not perform precise vesicourethral anastomosis. In fact, compared to LRP or RALRP, LESSRP has several disadvantages. First, it does not allow the laparoscope and instruments to be moved freely in a limited space. Second, flexible laparoscopic instruments are not strong as compared with conventional laparoscopic instruments. This caused difficulty in suturing the vesicourethral site in our case. Third, the long distance between the homemade single-port device and the symphysis pubis is also a problem in suturing. For those reasons, we could not perform precise vesicourethral anastomosis and converted to conventional LRP in the current case.

We report a case of LESSRP using a homemade single-port device. It is thought that, although our technique may require a greater learning curve than conventional LRP and may increase operation time, new flexible or multifunctional laparoscopic instruments will make LESSRP feasible and easier. 


\begin{tabular}{c|l|l|l}
$\begin{array}{c}\text { Case Reports in } \\
\text { Oncology }\end{array}$ & $\begin{array}{l}\text { Case Rep Oncol 2010;3:445-450 } \\
\text { DOI: 10.1159/000322818 }\end{array}$ & $\begin{array}{l}\text { Published online: } \\
\text { December 1, 2010 }\end{array}$ & $\begin{array}{l}\text { O 2010 S. Karger AG, Basel } \\
\text { ISSN 1662-6575 } \\
\text { www.karger.com/cro }\end{array}$ \\
\hline
\end{tabular}

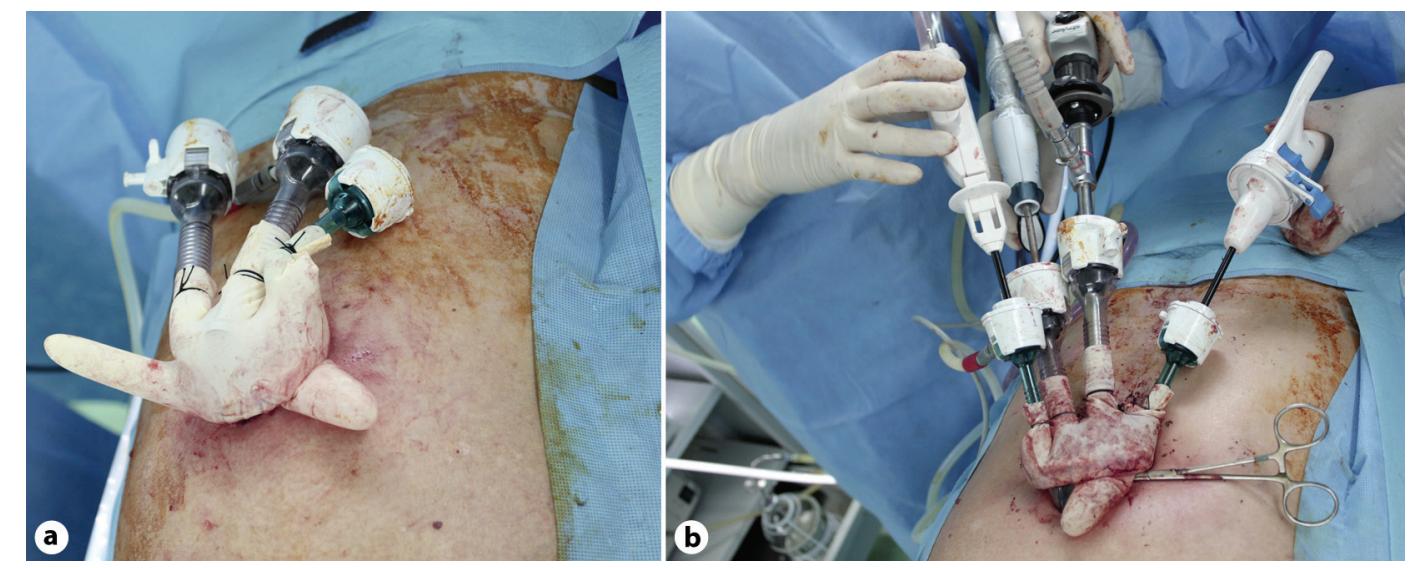

Fig. 1. Intraoperative photograph demonstrating the homemade single-port device (a) and the laparoscopic instrument configuration during laparoendoscopic single-site radical prostatectomy $(\operatorname{LESSRP})(\mathbf{b})$.

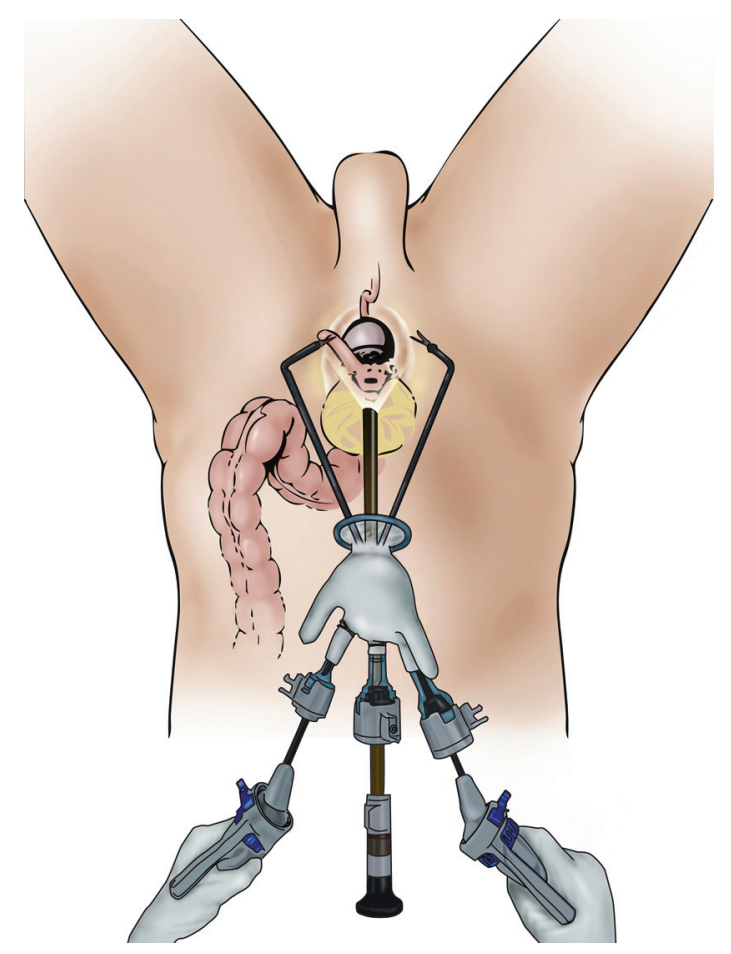

Fig. 2. Schematic illustration of a patient positioned in supine low lithotomy position. The homemade single-port device was inserted in the umbilical single incision. Rigid laparoscope and flexible instruments (LaparoAngle ${ }^{\circledR}$, Cambrige Endo, Framingham, Mass., USA) were used through the singleport device. 


\begin{tabular}{c|l|l|l}
$\begin{array}{c}\text { Case Reports in } \\
\text { Oncology }\end{array}$ & $\begin{array}{l}\text { Case Rep Oncol 2010;3:445-450 } \\
\text { DOI: 10.1159/000322818 }\end{array}$ & $\begin{array}{l}\text { Published online: } \\
\text { December 1, 2010 }\end{array}$ & $\begin{array}{l}\text { O 2010 S. Karger AG, Basel } \\
\text { ISSN 1662-6575 } \\
\text { www.karger.com/cro }\end{array}$ \\
\hline
\end{tabular}

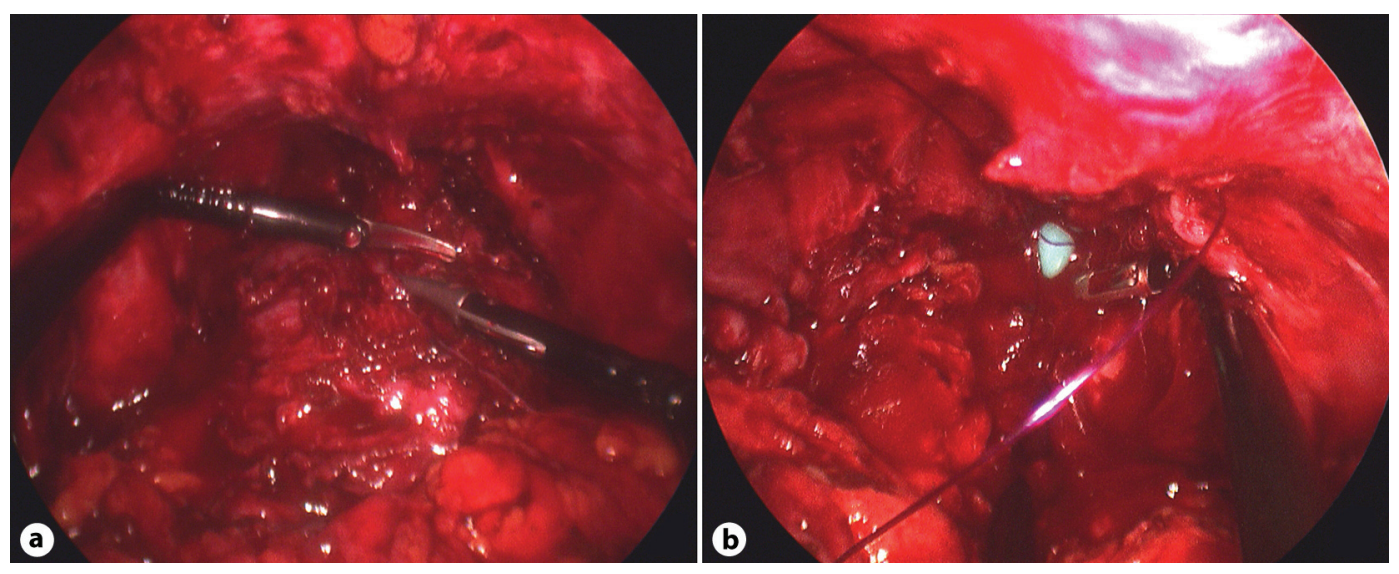

Fig. 3. Exposure of the prostate with use of LaparoAngle (Cambridge Endo) dissectors (a) and vesicourethral anastomosis by LaparoAngle dissectors $(\mathbf{b})$.
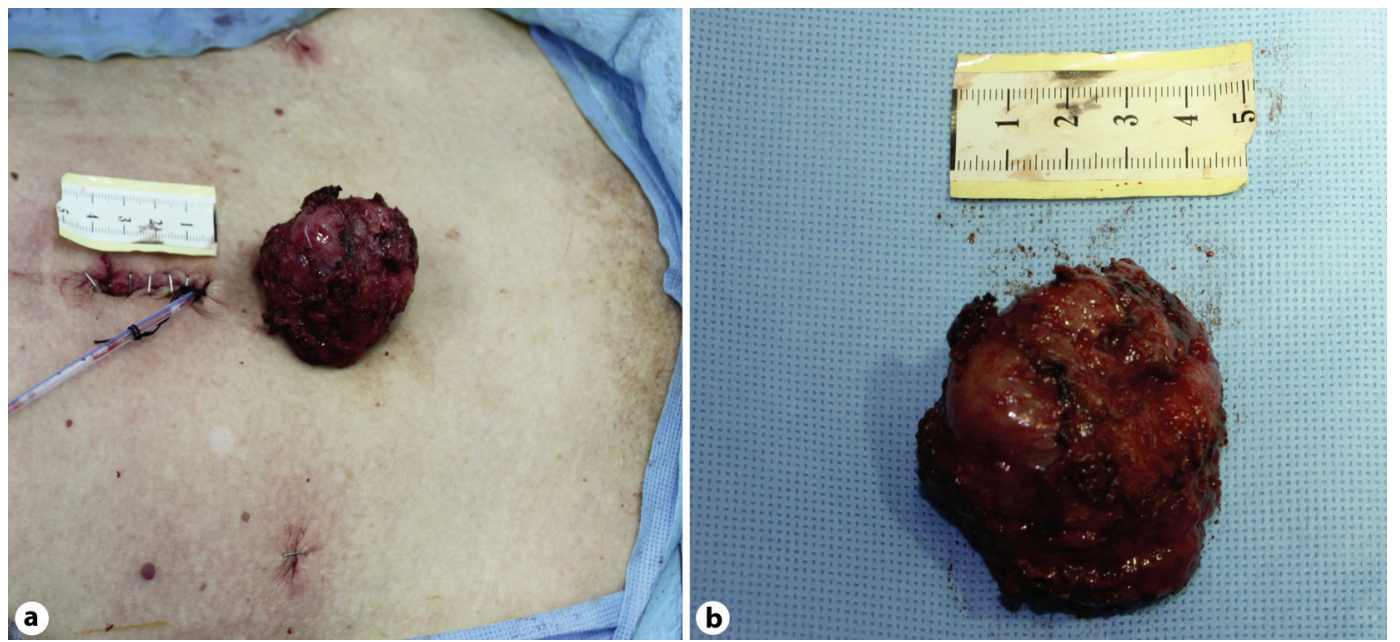

Fig. 4. External picture of an extracted prostate and reconstructed umbilical incision with two additional transcutaneous ports (a) and an extracted prostate which measured approximately $5 \mathrm{~cm}(\mathbf{b})$. 


\begin{tabular}{|c|c|c|c|}
\hline $\begin{array}{l}\text { Case Reports in } \\
\text { Oncolocy }\end{array}$ & $\begin{array}{l}\text { Case Rep Oncol 2010;3:445-450 } \\
\text { DOI: } 10.1159 / 000322818\end{array}$ & $\begin{array}{l}\text { Published online: } \\
\text { December 1, } 2010\end{array}$ & $\begin{array}{l}\text { @ } 2010 \text { S. Karger AG, Basel } \\
\text { ISSN } 1662-6575 \\
\text { www.karger.com/cro }\end{array}$ \\
\hline
\end{tabular}

\section{References}

1 Clayman RV, Kavoussi LR, Figenshau RS, Chandhoke PS, Albala DM: Laparoscopic nephroureterectomy: initial clinical case report. J Laparoendosc Surg 1991;1:343-349.

-2 Schuessler WW, Schulam PG, Clayman RV, Kavoussi LR: Laparoscopic radical prostatectomy: initial shortterm experience. Urology 1997;50:854-857.

3 Guillonneau B, el-Fettouh H, Baumert H, Cathelineau X, Doublet JD, Fromont G, Vallancien G: Laparoscopic radical prostatectomy: Oncological evaluation after 1,000 cases at Montsouris Institute. J Urol 2003;169:12611266.

-4 Abbou CC, Salomon L, Hoznek A, Antiphon P, Cicco A, Saint F, Alame W, Bellot J, Chopin DK: Laparoscopic radical prostatectomy: preliminary results. Urology 2000;55:630-634.

-5 Kaouk JH, Haber GP, Goel RK, Desai MM, Aron M, Rackley RR, Moore C, Gill IS: Single-port laparoscopic surgery in urology: initial experience. Urology 2008;71:3-6.

6 Schulam PG, Link RE: Laparoscopic radical prostatectomy. World J Urol 2000;18:278-282.

7 Box G, Averch T, Cadeddu J, Cherullo E, Clayman R, Desai M, Frank I, Gettman M, Gill I, Gupta M, Haber GP, Kaouk J, Landman J, Lima E, Ponsky L, Rane A, Sawyer M, Humphreys M: Nomenclature of natural orifice translumenal endoscopic surgery (NOTES) and laparoendoscopic single-site surgery (LESS) procedures in urology. J Endourol 2008;22:2575-2581.

-8 Rane A, Ahmed S, Kommu SS, Anderson CJ, Rimington PD: Single-port 'scarless' laparoscopic nephrectomies: the United Kingdom experience. BJU Int 2009;104:230-233.

-9 Sotelo RJ, Astigueta JC, Desai MM, Canes D, Carmona O, De Andrade RJ, Moreira O, Lopez R, Velasquez A, Gill IS: Laparoendoscopic single-site surgery simple prostatectomy: initial report. Urology 2009;74:626-630.

10 Kaouk JH, Goel RK, Haber GP, Crouzet S, Desai MM, Gill IS: Single-port laparoscopic radical prostatectomy. Urology 2008;72:1190-1193. 